Supporting Information for

\title{
Gas Generating Polymer Particles: Reducing the Decomposition Temperature of Poly(tert-Butyl Methacrylate) Side Chains Using an Encapsulated Acid Catalyst Approach
}

Ibrahim Eryazici, ${ }^{1,{ }^{*} \dagger}$ Matthew C. D. Carter, ${ }^{2, \dagger}$ Wesley Sattler, ${ }^{2}$ Jian Yang, ${ }^{3}$ Scott Wills, ${ }^{4}$ Francois J. Huby, ${ }^{4}$ Irina Peshenko, ${ }^{4}$ and Patricia Ansems-Bancroft ${ }^{3}$

${ }^{1}$ Dow Coating Materials, ${ }^{2}$ Core Research \& Development, and ${ }^{4}$ Analytical Sciences, The Dow Chemical Company, 400 Arcola Rd., Collegeville, PA, 19426; ${ }^{3}$ Core Research \& Development, The Dow Chemical Company, 240 Abner Jackson Parkway, Lake Jackson, TX, 77566.

*E-mail: ieryazici@dow.com; ${ }^{\dagger}$ These authors contributed equally. 


\section{Materials and Methods}

Materials. Tert-butyl methacrylate ( $t$-BMA, 98\%), 2-acrylamido-2-methyl-1-propanesulfonic acid (AMPS, 99\%), ammonium persulfate (APS, 98\%), tert-butyl hydroperoxide $(t$-BHP, 70 wt $\%$ in water), isoascorbic acid (IAA, 98\%), iron (II) sulfate heptahydrate (>99\%), methanol (HPLC grade, 99.9\%) and acetonitrile (HPLC grade, 99.\%) were obtained from Sigma-Aldrich (Milwaukee, WI). Sodium lauryl sulfate (SLS, $28 \mathrm{wt} \%$ in water) and Polystep A-16-22 sodium dodecylbenzene sulfonate (SDBS, $22 \mathrm{wt} \%$ in water) were obtained from Stepan (Northfield, IL). SIPOMER PAM-200 phosphate ester of PPG monomethacrylate (PAM-200, 97\%) was obtained from Solvay (Bristol, PA). 2-Sulfoethyl methacrylate (2-SEM, 90\%) was obtained from Polysciences (Warrington, PA). Butyl acrylate (BA, 99\%) and TERGITOL ${ }^{\mathrm{TM}}$ 15-S-7 Surfactant ( $>95 \%)$ were obtained from The Dow Chemical Company (Midland, MI). Deuterated DMSO- $d_{6}$ $(99.96 \%)$ and $\mathrm{D}_{2} \mathrm{O}(99.96 \%)$ ampules were obtained from Cambridge Isotopes Labs (Tewksbury, MA). All reagents and chemicals were used as received unless otherwise specified.

Synthesis of $t$-BMA latex particles with various acid comonomers ( $\sim 300 \mathrm{~nm}$ diameter). The synthesis was carried out using a 3 L, 4-neck round bottom flask outfitted with a condenser, overhead stirrer, and thermocouple. Deionized water (1200.0 g) was added to the flask, and the contents of the reactor were stirred at $150 \mathrm{rpm}$ and heated to $88^{\circ} \mathrm{C}$ under a nitrogen atmosphere. In a separate vessel, a monomer emulsion (M.E.) containing deionized water (290.0 g), SDBS (4.7 $\mathrm{g}, 22.0 \mathrm{wt} \%$ in water), $t$-BMA $(679.0 \mathrm{~g})$, and BA (75.0 g) was prepared. A solution of APS (3.0 g in $30.0 \mathrm{~g}$ water) was added to the reactor with rinsing (10.0 $\mathrm{g}$ water), followed by the addition of a polymer seed particle $[70.0 \mathrm{~g}, 44.7 \mathrm{wt} \%$ in water, $95 \mathrm{~nm}$ diameter, $52 n$-butyl acrylate (BA)/46.5 methyl methacrylate (MMA)/1.5 methacrylic acid (MAA); all values given on a wt basis] with rinsing (70.0 g water), which caused the temperature of the reactor to drop to $80^{\circ} \mathrm{C}$. After a 5 min 
hold, the M.E. and a solution of APS (1.0 g in $120.0 \mathrm{~g}$ water) were fed simultaneously into the reactor at a rate of $2.1 \mathrm{~g} / \mathrm{min}$ and $0.25 \mathrm{~g} / \mathrm{min}$, respectively, over $10 \mathrm{~min}$, at a temperature of 80 $82{ }^{\circ} \mathrm{C}$. The M.E. and APS solution feed rates were increased to $4.2 \mathrm{~g} / \mathrm{min}$ and $0.5 \mathrm{~g} / \mathrm{min}$ for 20 min, and then to $8.4 \mathrm{~g} / \mathrm{min}$ and $1.0 \mathrm{~g} / \mathrm{min}$ for $110 \mathrm{~min}$. Upon completion of the feeds, the M.E. and APS solution vessels were rinsed into the reactor with $40.0 \mathrm{~g}$ and $10.0 \mathrm{~g}$ of water, respectively. The reactor was then held for an additional $1 \mathrm{hr}$ at $85^{\circ} \mathrm{C}$ and then cooled to room temperature and filtered through 325 mesh to give Latex-1. The final latex had a solids content of $29.9 \mathrm{wt} \%$ (as determined by allowing $\sim 1 \mathrm{~g}$ of wet latex to dry overnight at room temperature), a glass transition temperature $\left(T_{\mathrm{g}}\right)$ of $79.4{ }^{\circ} \mathrm{C}$, and a particle size of $328 \mathrm{~nm}$. The final percent conversions of BA and $t$-BMA were $>99 \%$ and $>98 \%$, respectively (as determined by GC and HPLC, respectively). The overall final polymer composition was 13.2 BA/83.0 t-BMA/3.7 MMA/0.1 MAA (weight basis; the $95 \mathrm{~nm}$ diameter seed accounted for $7.8 \mathrm{wt} \%$ of the overall polymer composition). In cases where acid comonomers were included in the composition, a portion of $t$-BMA was removed from the M.E. and replaced with an equal mass of acid comonomer in order to achieve the desired composition, as follows. Latex-2: $20.8 \mathrm{~g}$ 2-SEM, final solids content $24.6 \%, T_{\mathrm{g}}=79.9^{\circ} \mathrm{C}$, particle size $330 \mathrm{~nm}$, and overall composition 13.2 BA/81.0 t-BMA/2.0 2-SEM/3.7 MMA/0.1 MAA. Latex-3: $20.8 \mathrm{~g}$ AMPS, final solids content $24.9 \%, T_{\mathrm{g}}=84.1^{\circ} \mathrm{C}$, particle size $324 \mathrm{~nm}$, and overall composition 13.2 BA/81.0 t-BMA/2.0 AMPS/3.7 MMA/0.1 MAA. Latex-4: 41.6 g PAM-200, final solids content $22.7 \%, T_{\mathrm{g}}=80.2{ }^{\circ} \mathrm{C}$, particle size $336 \mathrm{~nm}$, and overall composition 13.2 BA/79.0 $t$-BMA/4.0 PAM-200/3.7 MMA/0.1 MAA. Latex-5: 4.0 g PAM-200, final solids content $24.1 \%, T_{\mathrm{g}}=99.4{ }^{\circ} \mathrm{C}$, particle size $291 \mathrm{~nm}$, overall composition $13.2 \mathrm{BA} / 82.5 t$-BMA/0.5 PAM200/3.7 MMA/0.1 MAA. In all cases, the final percent conversions of BA and $t$-BMA for Latex2 through Latex-5 were $>99 \%$ and $>98 \%$, respectively, 
Synthesis of $t$-BMA Latex Particles ( $\sim 600 \mathrm{~nm}$ diameter). The synthesis was carried out using a 3 L, 4-neck round bottom flask outfitted with a condenser, overhead stirrer, and thermocouple. Deionized water (1200.0 g) was added to the flask, and the contents of the reactor were stirred at $150 \mathrm{rpm}$ and heated to $92{ }^{\circ} \mathrm{C}$ under a nitrogen atmosphere. In a separate vessel, a M.E. containing deionized water (250.0 g), SDBS (6.0 g, $22.0 \mathrm{wt} \%$ in water), PAM-200 (4.0 g), $t$-BMA (675.0 g), and BA (75.0 g) was prepared. A solution of APS ( $3.0 \mathrm{~g}$ in $30.0 \mathrm{~g}$ water) was added to the reactor with rinsing (10.0 $\mathrm{g}$ water), followed by the addition of the polymer seed particle (Latex-5; 330.0 g, $29.9 \mathrm{wt} \%$ in water) with rinsing (50.0 g water), which caused the temperature of the reactor to drop to $78{ }^{\circ} \mathrm{C}$. After a $5 \mathrm{~min}$ hold, the M.E. and a solution of APS ( $1.0 \mathrm{~g}$ in $130.0 \mathrm{~g}$ water) were fed simultaneously into the reactor at a rate of $2.1 \mathrm{~g} / \mathrm{min}$ and $0.25 \mathrm{~g} / \mathrm{min}$, respectively, over $10 \mathrm{~min}$, at a temperature of $82-84{ }^{\circ} \mathrm{C}$. The M.E. and APS solution feed rates were increased to $4.2 \mathrm{~g} / \mathrm{min}$ and $0.5 \mathrm{~g} / \mathrm{min}$ for $20 \mathrm{~min}$, and then to $8.4 \mathrm{~g} / \mathrm{min}$ and $1.0 \mathrm{~g} / \mathrm{min}$ for $110 \mathrm{~min}$. Upon completion of the feeds, the M.E. and APS solution vessels were rinsed into the reactor with $40.0 \mathrm{~g}$ and $10.0 \mathrm{~g}$ of water, respectively. The stirring rate was then decreased to $100 \mathrm{rpm}$ and the reactor was held for an additional $1 \mathrm{hr}$ at $85^{\circ} \mathrm{C}$, and then cooled to room temperature and filtered through $325 \mathrm{mesh}$ to give Latex-6. The final latex had a solids content of $29.7 \%, T_{\mathrm{g}}=87.8^{\circ} \mathrm{C}$, and a particle size of $563 \mathrm{~nm}$. The final percent conversions of BA and $t$-BMA were $>99 \%$ and $>98 \%$, respectively. The overall final polymer composition was 10.3 BA/88.8 $t$-BMA/0.4 MMA/0.5 PAM-200 (weight basis; the original $95 \mathrm{~nm}$ diameter seed accounted for $0.9 \mathrm{wt} \%$ of the overall polymer composition). Synthesis of $t$-BMA Latex Particles Containing Cat-1 ( $1 \mu \mathrm{m}$ diameter). The synthesis was carried out using a $1 \mathrm{~L}$, 4-neck round bottom flask outfitted with a condenser, overhead stirrer, and thermocouple. Deionized water (190.0 g) and the polymer seed particle (Latex-6, 119.0 g, 28.1\% solids) were added to the flask, and the contents of the reactor were stirred at $150 \mathrm{rpm}$ and heated 
to $70{ }^{\circ} \mathrm{C}$ under a nitrogen atmosphere. In a separate vessel, a M.E. containing deionized water (43.8 g), SDBS (1.1 g, 22.0 wt\% in water), PAM-200 (0.7 g), $t$-BMA (123.5 g), and BA (13.1 g), was prepared. Separately, solutions of $70 \mathrm{wt} \% t$-BHP $(0.66 \mathrm{~g}$ in $35.0 \mathrm{~g}$ water $)$ and IAA $(0.53 \mathrm{~g}$ in 35.0 water) were prepared and loaded into plastic syringes. At $70{ }^{\circ} \mathrm{C}$, a solution of iron (II) sulfate heptahydrate $(5.0 \mathrm{~g}, 0.15 \mathrm{wt} \%$ in water $)$ was added to the reactor with rinsing (5.0 g water). After a 1 min hold, the M.E. and the $t$-BHP/IAA solutions were fed simultaneously into the reactor at a rate of $0.75 \mathrm{~g} / \mathrm{min}$ and $0.12 \mathrm{~g} / \mathrm{min}$, respectively, over $20 \mathrm{~min}$, at a temperature of $69-71{ }^{\circ} \mathrm{C}$. The M.E. and cofeed solution feed rates were then increased to $1.5 \mathrm{~g} / \mathrm{min}$ and $0.25 \mathrm{~g} / \mathrm{min}$, respectively, for 110 min. The M.E. was fed over 130 min total, and upon completion of the M.E feed, the M.E. vessel was rinsed into the reactor with $20.0 \mathrm{~g}$ of water. The $t$-BHP/IAA solutions were fed over $150 \mathrm{~min}$ total (i.e., the redox cofeed continued at $0.25 \mathrm{~g} / \mathrm{min}$ for $20 \mathrm{~min}$ after the M.E. feed was complete). Upon completion of the $t$-BHP/IAA solution cofeeds, the reactor was cooled to room temperature and filtered through 325 mesh to give Latex-7. The final latex had a solids content of $28.1 \%, T_{\mathrm{g}}=96.0^{\circ} \mathrm{C}$, and a particle size of $919 \mathrm{~nm}$. The final percent conversions of BA and $t$ BMA were $>99 \%$ and $>98 \%$, respectively. The overall final polymer composition was $9.8 \mathrm{BA} / 89.5$ $t$-BMA/0.5 PAM-200 (weight basis; the original $95 \mathrm{~nm}$ diameter seed accounted for $0.2 \mathrm{wt} \%$ of the overall polymer composition). Latex-8, an analogous sample with the same polymer composition but containing $1.5 \mathrm{wt} \%$ Cat-1 (based on the overall polymer mass) was obtained using the above procedure. Cat-1 (2.8 g) replaced an equal mass of (and was dissolved in) $t$-BMA in the M.E. prior to synthesis. Samples were removed at pre-determined times in-process and immediately dried in aluminum pans overnight at room temperature for HPLC determination of the hydrolysis of Cat-1. Latex-8 had a solids content of $27.8 \%$ and a particle size of $993 \mathrm{~nm}$. The 
$T_{\mathrm{g}}$ was not determined by DSC due to the presence of Cat-1. The final percent conversions of BA and $t$-BMA were similar to Latex-7.

Headspace Gas Chromatography (GC) - Residual BA Method. Headspace gas chromatography for the determination of residual BA in latex samples was performed using a Agilent $6890 \mathrm{~N}$ gas chromatograph equipped with a Restek RX-200 30 m x $0.32 \mathrm{~mm}$ (ID) x 1.0 $\mu \mathrm{m}$ df column, Split/Spitless injector, flame ionization detector (FID), and an Agilent 7697A headspace autosampler. Samples were prepared for analysis by directly weighing a known mass of undiluted latex into a headspace vial containing a known mass of ethylene glycol diethyl ether internal standard (5000 pppm in deionized water). The carrier gas was ultrahigh purity helium, the make-up gas was $\mathrm{N}_{2}$, and the fuel gases were $\mathrm{H}_{2} /$ air. The instrument operated at a column head pressure of $9.5 \mathrm{psi}$, column flow rate of $2.1 \mathrm{~mL} / \mathrm{min}$, make-up flow rate of $20 \mathrm{~mL} / \mathrm{min}$, hydrogen flow rate (FID) of $40 \mathrm{~mL} / \mathrm{min}$, and air flow rate (FID) of $400 \mathrm{~mL} / \mathrm{min}$. The temperature program parameters were as follows: $40{ }^{\circ} \mathrm{C}$ intial set temperature, $3 \mathrm{~min}$ equilibration time, $20{ }^{\circ} \mathrm{C} / \mathrm{min}$ to $245^{\circ} \mathrm{C}$ ramp, 5 min final time, cool to $40{ }^{\circ} \mathrm{C}$, and inlet temperature of $180^{\circ} \mathrm{C}$. The headspace parameters were as follows: $10 \mathrm{~min}$ vial equilibration, $0.1 \mathrm{~min}$ vial pressurization, $0.3 \mathrm{~min}$ injection, $0.1 \mathrm{~min}$ loop equilibration, $0.05 \mathrm{~min}$ loop fill, with a loop temperature of $140^{\circ} \mathrm{C}$, oven temperature of $130^{\circ} \mathrm{C}$, and transfer line temperature of $180^{\circ} \mathrm{C}$. The instrument was calibrated from 5 to 10000 ppm using high purity BA (99\%) standards (obtained from Sigma-Aldrich, Milwaukee, WI).

Ultra High Pressure Liquid Chromatography (UHPLC) - Residual $t$-BMA Method. UHPLC for the determination of residual $t$-BMA in latex samples was performed using a Waters $\mathrm{H}$ Class UPLC equipped with a Waters Acquity HSS T3 $1.8 \mu \mathrm{m}$ VanGuard Pre-Column $(2.1$ x 5 mm), Waters Acquity UPLC HSS T3 $1.8 \mu \mathrm{m}(2.1 \times 150 \mathrm{~mm})$ column, Waters Acquity photodiode array (PDA) detector, and autosampler. Latex samples for analysis were prepared by $\sim 100-1000 \mathrm{X}$ 
dilution of a known mass of sample in a known mass of methanol/water (80:20 wt:wt). The samples were agitated for $1 \mathrm{hr}$ at room temperature and then centrifuged at $100000 \mathrm{rpm}$ for 15 min at $20^{\circ} \mathrm{C}$ using a Beckman Coulter Optima MAX-XP Ultracentrifuge. The samples were then filtered through a $0.2 \mu \mathrm{m}$ PTFE syringe filter and $2.0 \mu \mathrm{L}$ of sample solution was injected into the instrument. The instrument operated at a flow rate of $0.4 \mathrm{~mL} / \mathrm{min}$ at $40{ }^{\circ} \mathrm{C}$ using mobile phase (A): $2.5 \mathrm{mM}$ phosphoric acid in water, and mobile phase (B): $2.5 \mathrm{mM}$ phosphoric acid in acetonitrile. The solvent gradient was programmed as follows: $99.9 \%$ (A) for $0.5 \mathrm{~min}$, decreased to $60 \%$ (A) over $5.0 \mathrm{~min}$, decreased to $0 \%$ (A) over $0.5 \mathrm{~min}$, held at $100 \%$ (B) for $2.0 \mathrm{~min}$, decreased to $0.01 \%$ (B) over $0.5 \mathrm{~min}$, and then held at $99.9 \%$ (A) for $1.5 \mathrm{~min}$. The instrument was calibrated from 0.5 ppm to $100 \mathrm{ppm}$ with $t$-BMA (obtained from Sigma-Aldrich, as above).

Gel Permeation Chromatography (GPC). GPC separations were performed on a liquid chromatograph with an Agilent 1260 Infinity II isocratic pump, multicolumn thermostat, integrated degasser, autosampler, and refractive index detector. The system was equipped with two PLgel Mixed A columns $(300 \times 7.5 \mathrm{~mm}$ i.d., particle size $=20 \mu \mathrm{m})$ and a guard column $(50 \times 7.5 \mathrm{~mm}$ i.d.). The column oven and the refractive index detector operated at $40{ }^{\circ} \mathrm{C}$. The sample injection volume was $100 \mu \mathrm{L}$ and separations were performed with THF as the eluent at a flow rate of 1.0 $\mathrm{mL} / \mathrm{min}$. The instrument was calibrated with ten narrow-dispersity polystyrene standards from 580 - 6,800,000 Da. Data analysis was carried out using the Agilent GPC/SEC software package version A.02.01 (Build 9.34851).

Dynamic Light Scattering (DLS). DLS was performed using a Malvern Zetasizer Nano ZSP (Malvern, UK). The method assumed a refractive index of 1.479, and particle size is reported as the z-average particle size diameter, from an average of 3 runs of 10 scans. 
Differential Scanning Calorimetry (DSC). Samples were prepared for DSC experiments by drying $\sim 15 \mathrm{mg}$ of wet latex in a DSC pan in an oven at $50{ }^{\circ} \mathrm{C}$ overnight. Data was obtained using a DSC 2950 (TA Instruments) over a temperature range of $\mathrm{T}=-90$ to $150{ }^{\circ} \mathrm{C}$ at a heating rate of $10{ }^{\circ} \mathrm{C} / \mathrm{min}$ under a nitrogen atmosphere. Samples were first cooled to $-90^{\circ} \mathrm{C}$, followed by heating to $150{ }^{\circ} \mathrm{C}$.

Synthesis of Cat-1. The acid amplifier Cat-1 was synthesized as described previously (see S. Kruger, et al. J. Am. Chem. Soc. 2009, 131, 9862-9863). 3-Methyl-1,3-butanediol (20.2, 0.194 mol) was added to a $250 \mathrm{~mL}$ three-neck round bottom flask. The flask was placed under nitrogen and cooled to $\sim 0{ }^{\circ} \mathrm{C}$ in an ice/water bath. Anhydrous pyridine ( $\sim 125 \mathrm{~g}$ ) was added by cannula transfer and, to this clear solution, $p$-toluenesulfonyl chloride ( $24.8 \mathrm{~g}, 0.130 \mathrm{~mol})$ was added portion-wise over $\sim 15$ min under nitrogen atmosphere. After $\sim 5 \mathrm{~min}$, complete solubilization of the $p$ toluenesulfonyl chloride gave a light yellow, clear solution. After $\sim 15$ min, a white solid began to precipitate out of the reaction mixture. After $3 \mathrm{hr}$ at $\sim 0^{\circ} \mathrm{C}$, the flask was allowed to warm to room temperature and the mixture was diluted with $\sim 200 \mathrm{~mL}$ of ethyl acetate and transferred to a separatory funnel. The organic phase was washed with $2 \mathrm{M} \mathrm{HCl}(3 \times 250 \mathrm{~mL})$, saturated sodium bicarbonate $(1 \times 175 \mathrm{~mL})$, and saturated sodium chloride $(1 \times 175 \mathrm{~mL})$. The organic phase was dried over sodium sulfate and the solvent was removed under reduced pressure to give the product as a clear, colorless viscous oil. The product was further dried under high vacuum and crystallized upon standing at $-5^{\circ} \mathrm{C}$ to yield long, thin white crystals. Yield, $74.4 \% .{ }^{1} \mathrm{H}$ NMR $(300 \mathrm{MHz}$, DMSO$\left.d_{6}\right): \delta 7.79(d, 2 \mathrm{H}, \mathrm{Ar}, J=8.1 \mathrm{~Hz}), 7.49(d, 2 \mathrm{H}, \mathrm{Ar}, J=8.1 \mathrm{~Hz}), 4.10\left(t, 2 \mathrm{H},-\mathrm{CH}_{2^{-}}, J=7.3 \mathrm{~Hz}\right)$, $2.42\left(s, 3 \mathrm{H},-\mathrm{CH}_{3}\right), 1.69\left(t, 2 \mathrm{H},-\mathrm{CH}_{2^{-}}, J=7.3 \mathrm{~Hz}\right), 1.03\left(s, 6 \mathrm{H},-\left(\mathrm{CH}_{3}\right)_{2}\right)$.

Determination of the Hydrolysis Kinetics of Cat-1 by ${ }^{1} \mathrm{H}$ NMR Spectroscopy. A solution of $2.0 \mathrm{~mL} \mathrm{D}_{2} \mathrm{O}$ in $4.0 \mathrm{~mL}$ DMSO- $d_{6}$ was prepared, and then added to $\sim 250 \mathrm{mg}$ of Cat-1 in a glass 
vial ( $\sim 120 \mathrm{~mol} \mathrm{D}_{2} \mathrm{O}: 1 \mathrm{~mol}$ Cat-1). The resulting solution was divided into $0.75 \mathrm{~mL}$ aliquots, each was placed in an NMR tube, and the samples were placed in a water bath at $80^{\circ} \mathrm{C}$. Sample tubes were removed at pre-determined times and cooled to room temperature for ${ }^{1} \mathrm{H}$ NMR analysis using a Bruker Avance 300 (300 MHz, average of 64 scans, relaxation delay of $2 \mathrm{~s}$ ). The degree of Cat-1 hydrolysis was determined by integrating the most downfield aromatic protons $(2 \mathrm{H}, 7.79 \mathrm{ppm})$ and comparing to the appearance of the most upfield aromatic protons of $p-\mathrm{TsOH}(2 \mathrm{H}, 7.15 \mathrm{ppm})$. Ultra High Pressure Liquid Chromatography (UHPLC) - Cat-1 Determination Method. UHPLC analysis was performed on Waters Acquity Ultra Performance Liquid Chromatography system equipped with a Waters Acquity CSH C18, $1.7 \mu \mathrm{m}(1 \mathrm{~mm} \times 50 \mathrm{~mm})$ column and a Waters Acquity photodiode array (DPA) detector. The instrument was externally calibrated by serial dilution of a standard solution of $p-\mathrm{TsOH}$ and Cat-1 $(\sim 2 \mathrm{wt} \%$ total in $0.02 \mathrm{wt} \%$ formic acid in methanol) from 0.3 to $100 \mathrm{ppm}$, using the absorption value at $222 \mathrm{~nm}$. Latex samples for analysis were prepared in duplicate by $\sim 40 \mathrm{X}$ dilution of a known mass of sample in a known mass of methanol. Samples were agitated for $1 \mathrm{hr}$ at room temperature and then centrifuged at $43000 \mathrm{rpm}$ for 15 min at $20^{\circ} \mathrm{C}$ using a Beckman Coulter Optima MAX-XP Ultracentrifuge. The samples were then filtered through a $0.2 \mu \mathrm{m}$ PTFE syringe filter and $2.0 \mu \mathrm{L}$ of sample solution was injected into the instrument. The instrument operated at a flow rate of $0.2 \mathrm{~mL} / \mathrm{min}$ at $40{ }^{\circ} \mathrm{C}$ using mobile phase (A): $0.05 \mathrm{vol} \%$ formic acid in water, and mobile phase (B): $0.05 \mathrm{vol} \%$ formic acid in acetonitrile. The solvent gradient was programmed as follows: $100 \%$ (A) for $1.0 \mathrm{~min}$, increased to $100 \%$ (B) over $2.0 \mathrm{~min}$, held at $100 \%$ (B) for $1.0 \mathrm{~min}$, decreased to $100 \%$ (A) over $0.5 \mathrm{~min}$, and then held at $100 \%$ (A) for $1.5 \mathrm{~min}$. Separate spike-recovery experiments were performed by adding either $p$ $\mathrm{TsOH}$ or Cat-1 (or both) to latex samples that did not contain analyte in order to confirm the validity of the method. 
Loading of $t$-BMA-Containing Latex Particles with $\boldsymbol{p}$-TsOH. A $5.0 \mathrm{~g}$ aliquot of Latex-7 (not containing Cat-1) was weighed into a glass vial. Based on the sample percent solids and polymer composition, the moles of $t$-BMA in the sample was determined. A pre-determined mass of $p$ TsOH (corresponding to a mol ratio of 1:100 or 1:10 $p$-TsOH:t-BMA) was weighed into a glass vial and dissolved in $0.5 \mathrm{~mL}$ acetone. The $p-\mathrm{TsOH}$ solution was then added to the pre-weighed sample of Latex-7 and stirred for $1 \mathrm{hr}$ at room temperature. The sample was then drop-cast into an aluminum pan and allowed to dry overnight at room temperature for TGA.

Thermal Gravimetric Analysis (TGA). Thermal decomposition experiments were performed using a TGA Q5000 (TA Instruments; software package V3.15, Build 263) equipped with an IR type furnace and using a heating ramp rate of 2,5 , or $10^{\circ} \mathrm{C} / \mathrm{min}$ under nitrogen, from $25^{\circ} \mathrm{C}$ to 350 ${ }^{\circ} \mathrm{C}$ (exact heating rates are specified in the main text). Samples were weighed onto Platinum-HT pans. Isothermal TGA experiments were performed by ramping at the instrument's maximum heating rate, and then holding at a set temperature of $90,110,130,150$, or $170{ }^{\circ} \mathrm{C}$ for $30 \mathrm{~min}$, as described in the main text. Generally, the instrument reached the set temperature within $60-90 \mathrm{sec}$ and did not overshoot the set temperature by more than $\sim 5^{\circ} \mathrm{C}$. Separately, TGA-MS experiments were performed using a TGA Q500 (TA Instruments; software V20.13, Build 39) coupled to a Agilent 5973 mass spectrometer (software package Agilent GC/MSD Chemstation G1701 EA Rev. E.01.00 SP2) operating over a scanning range of $m / z=14-300$. Samples were weighed onto TGA Platinum Pans (TA Instruments). The TGA furnace was closed, purged with helium, and then heated from room temperature using a temperature program as follows: $5.0{ }^{\circ} \mathrm{C} / \mathrm{min}$ to $350{ }^{\circ} \mathrm{C}$, followed by $20.0{ }^{\circ} \mathrm{C} / \mathrm{min}$ to $800{ }^{\circ} \mathrm{C}$. The effluent from the TGA furnace was continuously transferred to the MS via a heated interface and transfer line (the maximum temperature of the transfer path was $\sim 300{ }^{\circ} \mathrm{C}$ ). Sample sizes were limited to $\sim 2 \mathrm{mg}$ in TGA experiments to prevent 
physical disturbance to the pan when particles decomposed and generated gas. In certain cases, and as noted in the main text, small amounts of $1 \mathrm{M} \mathrm{HCl}_{(a q)}$ or $1 \mathrm{M} \mathrm{NaOH}_{(a q)}$ were used to adjust latex $\mathrm{pH}$ prior to drying for TGA analysis.

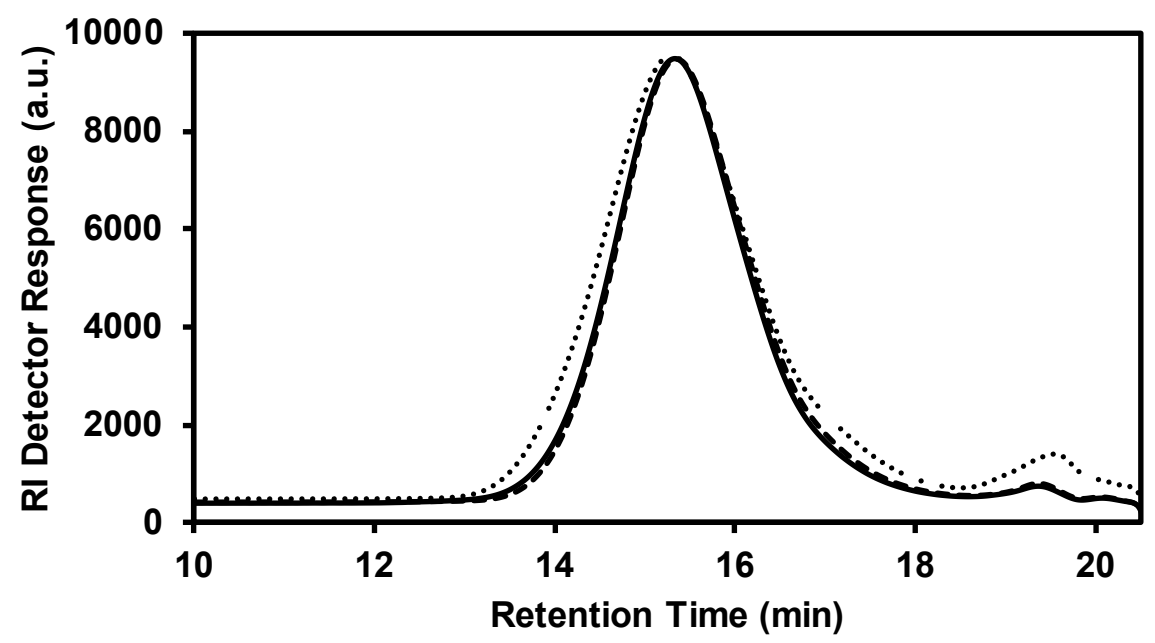

Figure S1. GPC chromatograms for select samples as described in the main text and as follows: Latex 6 (solid) $M_{\mathrm{n}}=36.0 \mathrm{kDa}, \emptyset=3.3$; Latex 7 (dots) $M_{\mathrm{n}}=32.6 \mathrm{kDa}, \emptyset=3.9$; Latex 8 (short dash) $M_{\mathrm{n}}=33.8 \mathrm{kDa}$, $Ð=3.1$. 

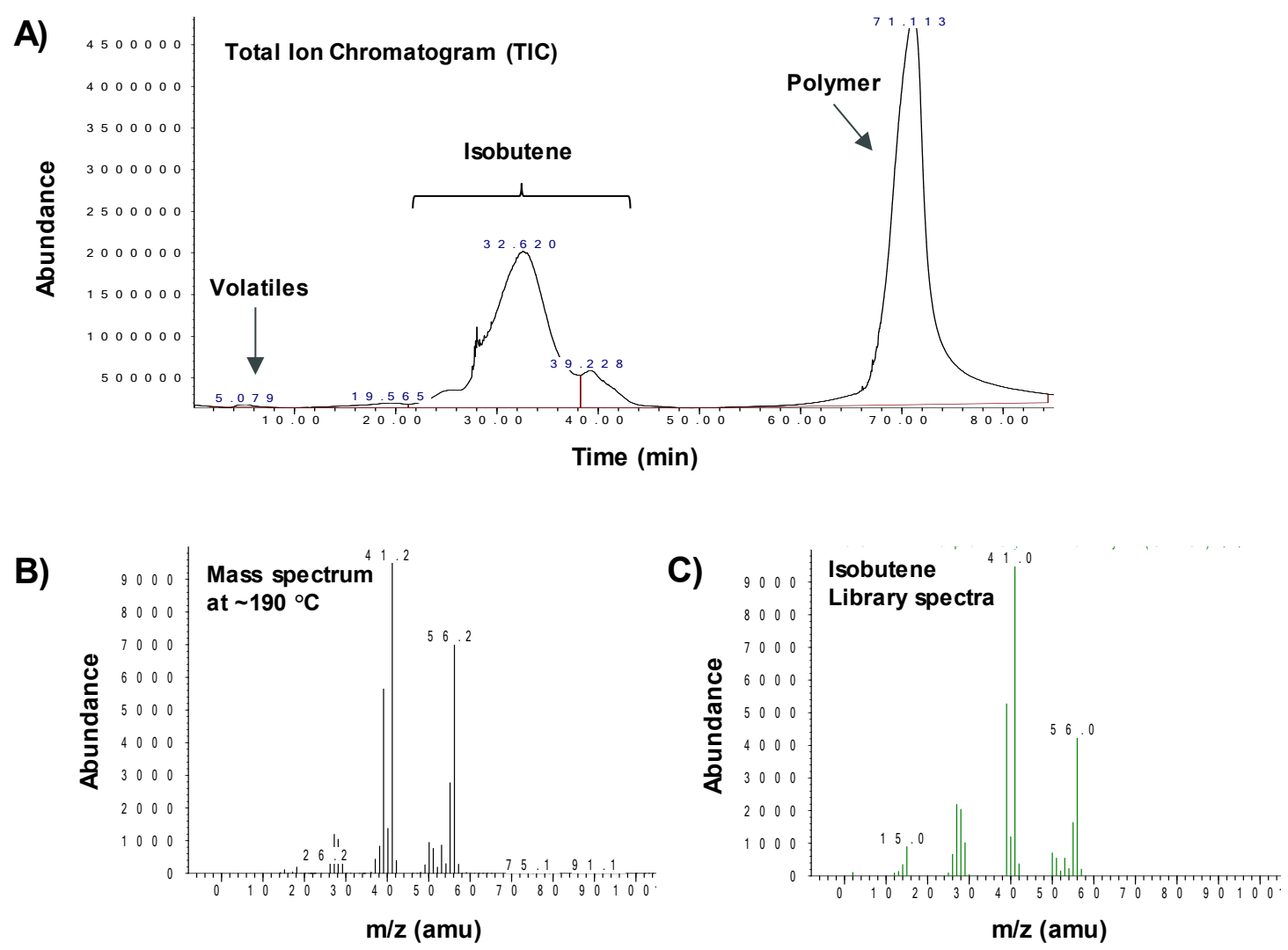

Figure S2. Representative TGA-MS data for the thermal decomposition of Latex-1. A) Total Ion Chromatogram (TIC) showing ion abundance over time. Volatile species, including small fractions of residual monomer, are observed near $\sim 5 \mathrm{~min}$, isobutene is observed from $\sim 19.5-39.2 \mathrm{~min}$, and species attributed to polymer backbone degradation are observed after $\sim 62 \mathrm{~min}$. The heating rate was $5{ }^{\circ} \mathrm{C} / \mathrm{min}$ to $300{ }^{\circ} \mathrm{C}$ (60 $\left.\mathrm{min}\right)$, at which point it was increased to $20^{\circ} \mathrm{C} / \mathrm{min}$ to thermolyze the residual sample polymer and clean the instrument. B) Extracted mass spectrum observed at $190^{\circ} \mathrm{C}$, that closely matches C) a library spectrum of isobutene. Note that the transfer line from the TGA sample chamber to the MS was heated in an oven to promote to material transfer; this temperature did not exceed $300^{\circ} \mathrm{C}$, but in repeat experiments, the presence of diisobutene (2,4,4-trimethyl-1-pentene) was occasionally observed. We attribute this observation to dimerization that may occur in the heated transfer line. 


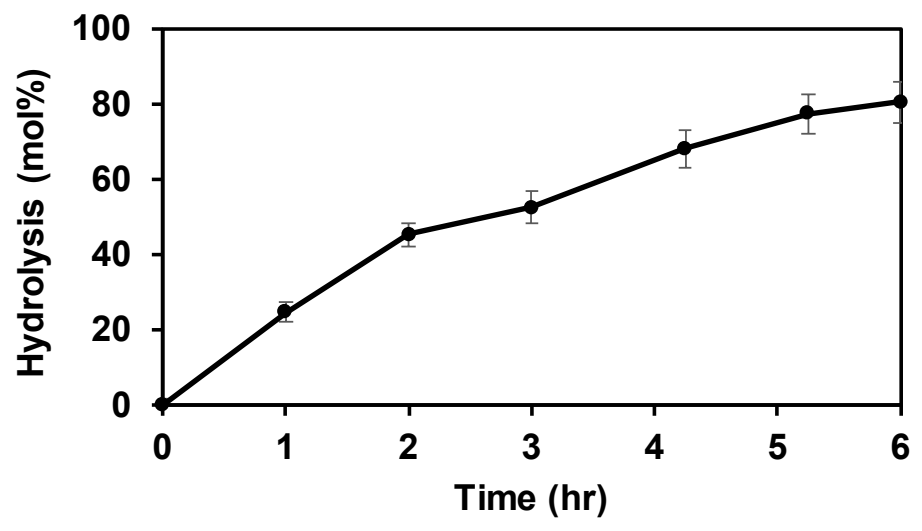

Figure S3. Plot of percent hydrolysis over time for Cat-1 dissolved in a solution of DMSO- $d_{6} / \mathrm{D}_{2} \mathrm{O}$, as determined by ${ }^{1} \mathrm{H}$ NMR spectroscopy (the solution contained a $\sim 120$ molar excess of $\mathrm{D}_{2} \mathrm{O}$ relative to Cat1). A stock sample solution was prepared and divided into separate NMR tubes. Samples were placed in a water bath at $80{ }^{\circ} \mathrm{C}$ and removed periodically for analysis at the time points indicated on the plot. The percent hydrolysis was determined by comparing the most upfield aromatic protons in Cat-1 $(2 \mathrm{H}, 7.79 \mathrm{ppm})$ to the most downfield aromatic protons of $p-\mathrm{TsOH}(2 \mathrm{H}, 7.15 \mathrm{ppm})$. Error bars were generated by assuming $\mathrm{a} \pm 5 \%$ error in the ${ }^{1} \mathrm{H}$ NMR integration values. Additional details are available in the Experimental Section of the main text.
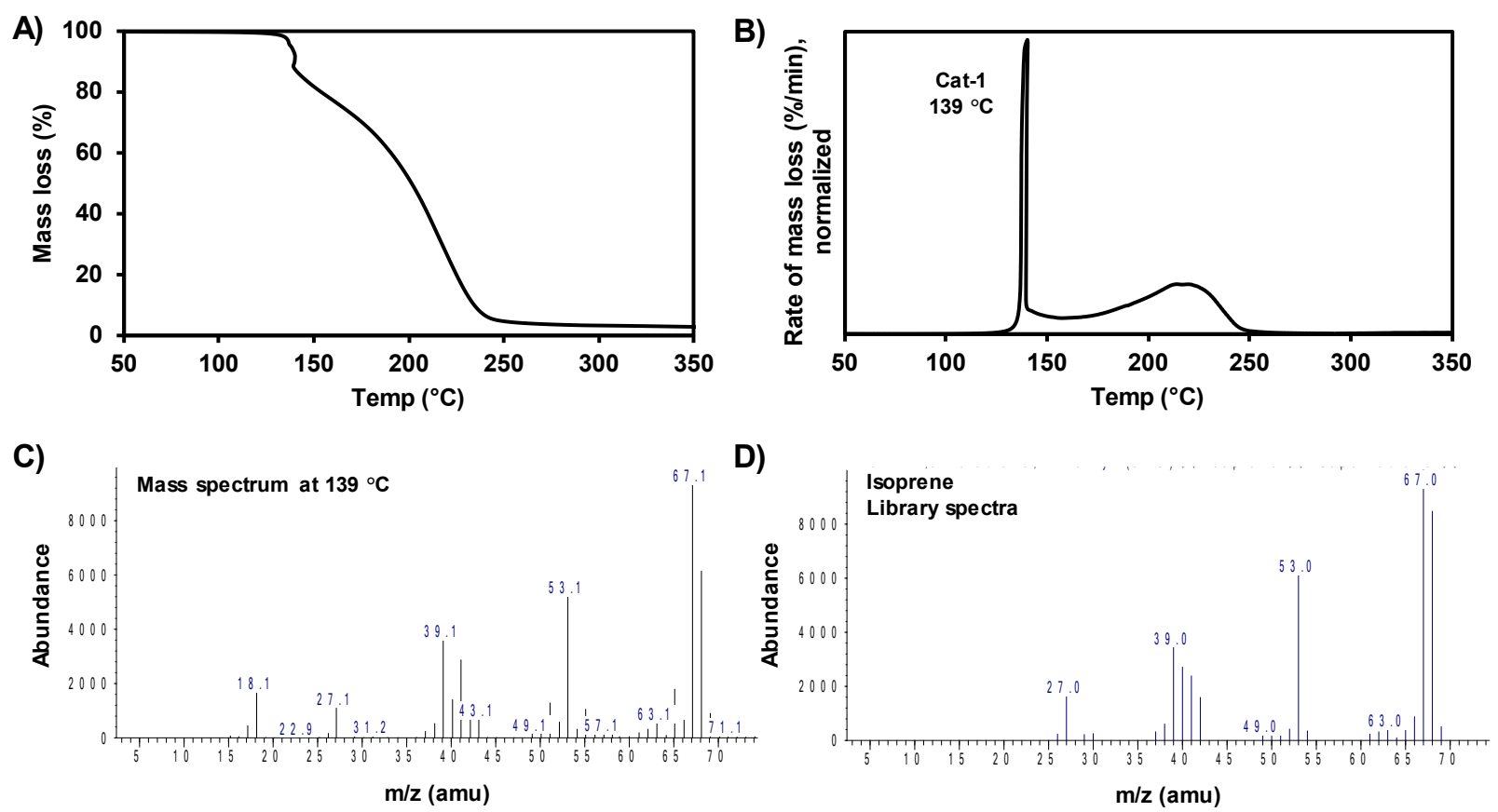

Figure S4. TGA-MS data and analysis for the thermal decomposition of Cat-1. A) Mass loss and B) mass loss rate (the derivative of mass loss with respect to temperature) plotted from 50 to $300{ }^{\circ} \mathrm{C}$. The heating rate was $5{ }^{\circ} \mathrm{C} / \mathrm{min}$. Cat-1 shows a sharp decomposition at $139^{\circ} \mathrm{C}$, as indicated on the plot. C) Mass spectrum observed at $139^{\circ} \mathrm{C}$, that closely matches D) a library spectrum of isoprene. 


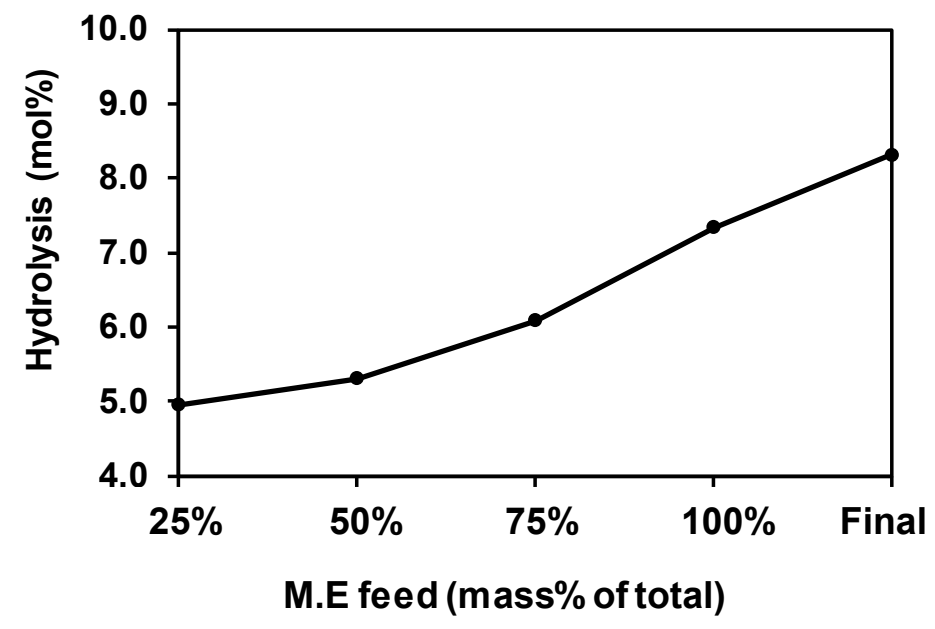

Figure S5. Plot of percent hydrolysis over time for Cat-1 during the Latex-8 emulsion polymerization process, as determined by HPLC. The data points in the plot correspond to the time at which 25, 50, 75, and $100 \%$ of the M.E. had been fed into the reactor. The final data point corresponds to the final sample, after post-processing steps. Error bars are not shown in the plot and are negligible; error was propagated using the $95 \%$ confidence interval $(\mathrm{CI})$ for the analytes. $\mathrm{CI}_{95 \%}(p-\mathrm{TsOH})=4 \mathrm{ppm} ; \mathrm{CI}_{95 \%}(\mathbf{C a t}-1)=20 \mathrm{ppm}$.

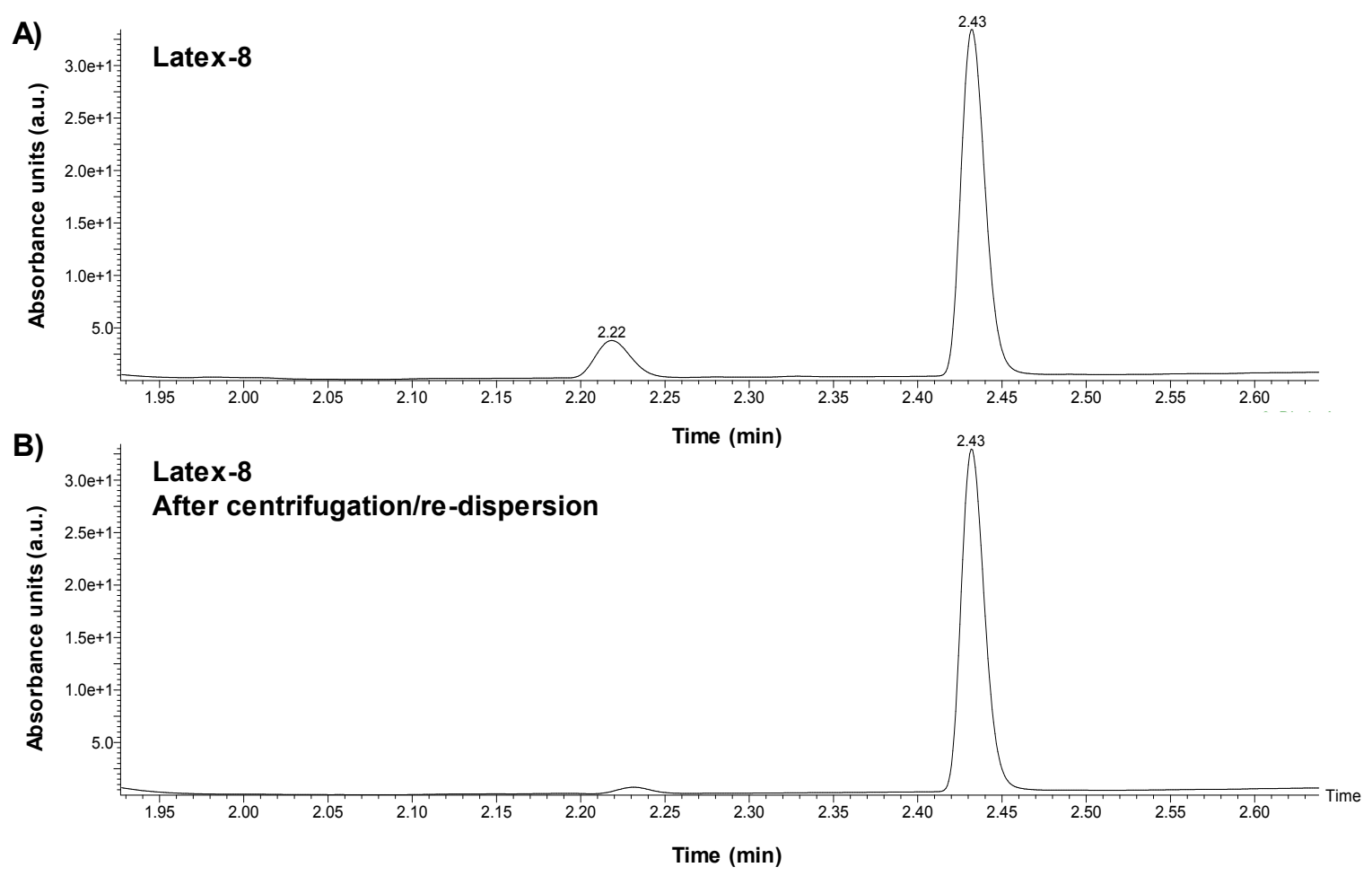

Figure S6. HPLC-UV chromatograms for the analysis of $p$-TsOH and Cat-1 in A) Latex-8 and B) Latex-8 after centrifugation and re-dispersion in fresh water. The peak centered at $2.22 \mathrm{~min}$ corresponds to $p$-TsOH and the peak at 2.43 min corresponds to Cat-1. Within error, the integration values of the Cat-1 peak in A) and in B) are equal. The data show that centrifugation/re-dispersion of Latex-8 removed the $p$-TsOH byproduct arising from the in-process hydrolysis of Cat-1. Comparison of the chromatograms also shows that Cat-1 is not extracted from the Latex-8 under these conditions, suggesting that it is localized within (and protected from hydrolysis by) the $t$ BMA-containing polymer particles. 